\title{
PENGEMBANGAN PERUMAHAN SUBSIDI UNTUK PEKERJA INDUSTRI DI KARAWANG
}

\author{
Hubert Winata ${ }^{1)}$, Parino Rahardjo ${ }^{2}$ \\ 1) Program Studi S1 PWK, Fakultas Teknik, Universitas Tarumanagara, hubert.345150020@stu.untar.ac.id \\ 2) Program Studi S1 PWK, Fakultas Teknik, Universitas Tarumanagara, parinor19@gmail.com
}

Masuk: 03-02-2020, revisi: 27-02-2020, diterima untuk diterbitkan: 09-05-2020 (doi: 10.24912/stupa.v2i1.7272)

\begin{abstract}
ABSTRAK
Rumah sudah menjadi sesuatu yang wajar dimiliki oleh masyarakat di berbagai kalangan, rumah tidak hanya berperan dalam memberikan perlindungan terhadap cuaca tetapi juga sebagai tempat untuk keluarga berkumpul dan menikmati waktu bersama dengan keluarga maupun orang lain. Tentu tidak semua orang bisa memiliki rumah dengan berbagai alasan, oleh sebab itu pemerintah melakukan intervensi dalam bentuk penyediaan subsidi. Namun mengapa tidak banyak perumahan subsidi dikarenakan pihak pengembang hanya melihat secara singkat seberapa besar pengembalian yang didapat pengembang tingkat pengembalian tersebut yang menentukan apakah pengembang mau atau tidak mengembangkan perumahan subsidi. Dengan pertanyaan tersebut dilakukanlah penelitian pengembangan perumahan perumahan subsidi untuk menunjukkan tingakt keuntungan yang akan didapatkan seorang pengembang beserta lamanya pengembalian modal. Analisis yang dilakukan yakni analisis lokasi, analisis tapak, analisis legalitan, analisis objek studi banding, analisis preferensi dan analisis keuangan. Alat analisis yang digunakan adalah analisis proximitas, Discounted Cashflow, Sensitivity Analysis, deskriptif dan kuatitatif. Hasil dari penelitian ini adalah besarnya pengembalian yang didapatkan pengembang pada tahun $n$, lama pengembaliannya dan persentase keuntungannya.
\end{abstract}

Kata Kunci: kawasan industri; keuntungan pengembang; perumahan subsidi; spesifikasi teknis

\begin{abstract}
Housing has always been a necessity in the lives of modern man. Anyone who was already working needs to own at least some form of housing. Development of a city plays a part in determining the prices of the housing sold whereas in the central and business district houses can be very expensive, the one's at the outskirt of the town can be cheaper or it can be which will be shown in this research. The government concerned offered developers a project which is known as Subsidized Housing, a house which is cheap with lots of benefits to encourage low income buyers. The industrial sector is known for its High Workforce which implies that a lot of manpower is involved, this creates ample market opportunities. Why don't we see a lot of subsidized housing? This concerns the fact that not all houses built for this manner yields enough profit to entice developers to actually build them. Thus the research for counting the actual benefit must be done in order to convince developers that there is an acceptable return to be gained when developing Subsidized Housing. The analysis conducted in this research include location analysis, site analysis, legality analysis, comparative object study analysis, preference analysis and financial analysis. The analytical tool used is the analysis of proximity, Discounted Cashflow, Sensitivity Analysis, descriptive and quantitative. The results of this study are the amount of returns obtained by the developer in $n$ years, the length of the return and the percentage of profits.
\end{abstract}

Keywords: building material; developer's profit; industrial district; subsidized housing 


\section{PENDAHULUAN}

Penduduk Karawang pada tahun 2018 mencapai 2,1 juta orang dan diperkirakan akan meningkat hingga mencapai 2,37 juta orang dalam kurum waktu 2 tahun. Dengan kabupaten Karawang yang memiliki berbagai jenis industri yang beroperasi, karyawannyapun juga perlu tempat tinggal yang nyaman dan terjangkau bagi pekerja tersebut. Tujuannya agar para pekerja memiliki akses yang mudah dari tampat mereka bekerja ke tempat tinggal.

Menurut Bupati Karawang, Cellica Nurrachadiana (2016),"Pembangunan penyokong industri, seperti pergudangan, pertokoan, dan perumahan tidak bisa lagi dihindari, seperti di Karawang Barat dan Karawang Timur," hal ini menunjukkan bahwa pengembangan di Karawang sudah dipastikan akan terjadi. Proyek rumah subsidi akan bekerja sama dengan PT Bank Tabungan Negara (BTN) dan BPJS Ketenagakerjaan kerja sama keduanya yakni menyediakan hunian bagi para pekerja di daerah yang akan dikembangkan dalam penelitian ini Karwang, hal ini sejalan dengan persetujuan yang dibuat oleh kedua belah pihak mengenai penyediaan kuota rumah subsidi beserta syarat pembelian rumah subsidi.

Karawang merupakan salah satu daerah industri yang baru baru ini diperhatikan pengembangannya sebagai salah satu Kota industry terbaru. Berbagai jenis industry juga sudah masuk di dalam Karawang dengan total luas industri mencapai lebih dari 50.000 ha tanah industri yang sudah terbangun dengan fasilitas pendukungnya seperti daerah perumahan Galuh Mas dan kawasan komersial Galuh Mas serta mal Karawang. Kurangnya minat pengembang dalam membuat perumahan subsidi menjadi permasalahan utama dalam penelitian ini terlebih lagi harga Materi bangunan sering mengalami fluktuasi terkadang harga bahan meningkat tinggi sehingga mempengaruhi harga jual rumah subsidi keuntungan yang didapat pengembang juga tidak menentu bisa untung bisa tidak padahal rumah subsidi masih diperlukan masyarakat menengah bawah yang memerlukan tempat tinggal terlebih lagi Pekerja industri yang harus berkomuter jauh untuk menuju ke tempat kerja.

Tabel 1. Kawasan Industri

\begin{tabular}{lc}
\hline \multicolumn{1}{c}{ Lokasi } & Luas (ha) \\
\hline Karawang International Industrial City & 13.800 \\
\hline PT Toyota Motor Manufacturing Indonesia & 10.300 \\
\hline Partners Industrial area (KIM) Karawang & 10.300 \\
\hline Kawasan Industri Surya Cipta & 15.500 \\
\hline Total Luas & 49.900 \\
\hline
\end{tabular}

Sumber: Olahan Penulis, 2019

Karawang memiliki beberapa kawasan industri yang terletak dekat jalan tol Jakarta-Cikampek dan Jalan Raya Pantura. Jenis produk industri yang dihasilkan terdapat berbagai macam dari produk makanan hingga produk mobil dan terdapat juga beberapa pabrik kertas dan kartu pos yang ada di daerah Karawang. Tujuan umum penelitian ini adalah menghitung tingkat pengembalian/keuntungan yang akan dihasilkan yang ditunjukkan dengan (NPV, IRR dan PI)

\section{KAJIAN LITERATUR}

\section{Perumahan Subsidi}

Perumahan subsidi merupakan salah satu upaya pemerintah dalam mengintervensi permasalahan kepadatan penduduk, rumah tersebut berbeda dalam hal harga dan desain serta bahah bangunannya. Perbedaan keduanya terletak pada siapa pembeli dari rumah tersebut dan bagaimana cara pembayaran rumah tersebut. Pemberian subsidi pada bidang perumahan merupakan salah satu kebijakan dari pemerintah terhadap penyediaan perumahan khususnya 
masyarakat berpenghasilan rendah. Dari koreksi harga pasar perumahan yang sangat tinggi tidak memberikan peluang kepada masyarakat berpenghasilan rendah untuk memiliki rumah. Pemberian subsidi terhadap masyarakat berpenghasilan rendah ini diharapkan akan mewujudkan masyarakat khususnya masyarakat berpenghasilan rendah untuk memiliki rumah.

\section{Kawasan Industri}

Kawasan indutri merupakan suatu wilayah dimana fungsi utama dari daerah tersebut adalah untuk pengolahan barang dan pergudangan dengan fasilitas pendukungnya. Definisi lain, menurut Industrial Development Handbook dari ULI (The Urban Land Institute), Washington DC (1975), kawasan industri adalah suatu daerah atau kawasan yang biasanya didominasi oleh aktifitas industri. Kawasan industri biasanya mempunyai fasilitas kombinasi yang terdiri atas peralatan-peralatan pabrik (industrial plants), penelitian dan laboratorium untuk pengembangan, bangunan perkantoran, bank, serta prasarana lainnya seperti fasilitas sosial dan umum yang mencakup perkantoran, perumahan, sekolah, tempat ibadah, ruang terbuka dan lainnya.

\section{Spektek (Spesifikasi Teknik)}

Pengertian spesifikasi teknik adalah suatu uraian atau ketentuan-ketentuan yang disusun secara lengkap dan jelas mengenai suatu barang, metode atau hasil akhir pekerjaan yang dapat dibeli, dibangun atau dikembangkan oleh pihak lain sehingga dapat memenuhi keinginan semua pihak yang terkait. Spesifikasi adalah bagian dari Dokumen Lelang proyek konstruksi yang menjelaskan persyaratan teknik pekerjaan yang dilelangkan. Tujuan spesifikasi yaitu untuk tercapainya produk akhir Pekerjaan yang memenuhi keinginan dari pemilik pekerjaan (owner).

\section{Discounted Cash Flow (DCF)}

Discounted Cash Flow atau biasa disebut DCF merupakan metode perhitungan untuk mengestimasi nilai maupun kelayakan dari suatu investasi proyek berdasarkan jumlah uang yang akan dihasilkan di tahun ke depan. Analisis DCF dilakukan untuk mencari present value ke dipan menggunakan suku bunga pada tahun masing masing.

Formula yang biasa digunakan dalam menghitung DCF yakni :

$$
\begin{array}{ll}
\qquad D C F=\frac{C F}{(1+r)^{\wedge} n} \\
\mathrm{CF} & =\text { Cash flow sekarang } \\
\mathrm{R} & =\text { Interst rate / Discount Rate } \\
\mathrm{N} & =\text { periode yang ingin dicari }
\end{array}
$$

\section{Sensitivitas}

Menurut Kasmir (2010: 275), Sensitivitas adalah pertimbangan risiko yang harus diperhitungkan berkaitan dengan sensitivitas perbankan. Sensitivitas terhadap risiko ini penting agar tujuan memperoleh laba dapat tercapai dan pada akhirnya kesehatan bank dapat juga terjamin. Sensitivitas pada penelititan ini akan digunakan dalam menghitung kelayakan investasi dengan beberapa faktor yang dibedakan seperti harga konstruksi rumah dan lama penjualan rumah.

\section{Net Present Value (NPV)}

NPV merupakan perbedaan anatara nilai uang yang dimiliki di masa sekarang dengan niali uang yang akan datang. NPV biasa digunakan untuk mencari apakah suatu proyek dapat menghasilakn keuntungan atau tidak. NPV dapat dicari dengan rumus : 
Present Value $=$ Cashflow $/\left((1+i)^{\wedge} n\right)$

I = Discount rate

$\mathrm{N} \quad=$ angka periode

Atau dalam menginput formula excel yakni, NPV (Discount rate,cashflow)

Internal Rate Return (IRR)

Merupakan tingkatan yang menyamakan nilai arus kas dengan biaya investasi tingkat suku bungan dimana NPV = 0 tujuan mencari irr yakni untuk melihat apakah sebuah proyek bisa menguntungkan atau tidak sama dengan NPV. Namun perbedaanya terletak pada cara perhitungannya dan cara penyajian datanya. IRR lebih melihat Tingkat pengembalian internal yang digunakan untuk mengevaluasi daya tarik suatu proyek atau investasi. Jika IRR dari proyek baru melebihi tingkat pengembalian yang disyaratkan perusahaan, proyek itu diinginkan. Jika IRR jatuh di bawah tingkat pengembalian yang disyaratkan, proyek harus ditolak.

\section{Profatibility Index (PI)}

Profitability Index adalah rasio dari nilai ekuitas dari sebuah investasi atau dapat disebut sebagai sebuah acuan mengenai seberapa besar pengembalian yang dapat diterima oleh developer. Aturan yang harus dituruti dari PI adalah bahwa PI harus lebih besar dari pada 1, contohnya jika suatu proyek apartemen dengan PI sebesar 1,03 maka profit yang akan dihasilkan proyek tersebut 3\% lebih besar dibanding investasi awal yang dilakuakan. PI dapat dihitung dengan rumus :

Profitability Index = ((NPV+Investasi Awal))/(Investasi Awal)

\section{METODE}

Data yang dikumpulkan selama proses penelitian adalah trend pertumbuhan penduduk Karawang, Harga satuan \& harga per unit dari spesifikasi teknik yang digunakan, data penggunaan lahan serta proximitas yang ada disekitar lahan pengembangan. Teknik pengumpulan data yang dilakukan dalam penelitian ini terbagi atas metode pengumpulan data primer dan pengumpulan data sekunder. Untuk metode pengumpulan data primer dilakukan dengan observasi/survei lapangan dan wawancara dengan pihak-pihak terkait beserta konsultasi professional dalam bidang bahan bangunan. Sementara untuk metode pengumpulan data sekunder dilakukan dengan dokumentasi, contoh anggaran biaya dan studi literatur.

Analisis yang dilakukan dalam penelitian ini meliputi analisis Lokasi \& Tapak, analisis Kebijakan, analisis Objek Studi, analisis Preferensi dan analisis Keuangan. Dalam penelitian ini menggunakan alat analisis Komparatif, Kualitatif dan Kuantitatif. Menurut Nazir (2005: 58) penelitian komparatif adalah sejenis penelitian deskriptif yang ingin mencari jawaban secara mendasar tentang sebabakibat, dengan menganalisis faktor-faktor penyebab terjadinya ataupun munculnya suatu fenomena tertentu. Alat kuantitatif membandingkan berbagai aspek objek maupun teori guna mendapatkan informasi. Kuantitatif digunakan saat analisis memerlukan perhitungan dalam proses analisis. Tujuan dari penelitian ini adalah untuk menyakinkan pengembang mengembangkan rumah subsidi dengan menunjukkan tingkat pengembalian serta syarat - syarat yang terkait, dengan melihat Rencana Anggaran Biaya.

\section{ANALISIS DAN DISKUSI}

Analisis Lokasi \& Tapak

Lokasi proyek yang penulis gunakan dalam pengembangan terletak di Jalan Veteran kabupaten Karawang dan berbatasan dengan kecamatan Karawang Barat dan Karawang Timur dengan luas 
total sebesar 2,8 Ha dengan lahan proyek dilewati oleh sungai dan sudah dalam tahap pembangunan. Akses menuju lokasi dapat ditempuh melalui jalan utama yakni jalan Veteran dan jalan Siliwangi. Aksesibilitias di Karawang memiliki kualitas yang buruk hal ini dapat dilihat dengan jalannya yang banyak lubangnya maupun beberapa jalan yang kondisi jalannya seperti belum pernah diluruskan, hal ini menyebabkan jalan yang berliku-liku menyebabkan pengendara mobil mengalami sedikit gangguan dalam mengemudi. Namun jika dilihat di dalam kota Karawangnya sendiri kondisi jalannya sudah bagus maupun masih banyak jalan-jalan kecil atau jalan pintas yang dapat dilewati oleh mobil. Akses di Karawang didominasi oleh jalan lokal yang luasnya tidak lebih dari $4 \mathrm{~m}$.

Karawang memiliki beberapa fungsi berdasarkan daerahnya mirip dengan Jakarta, dalam hal Karawang mayoritas komersial berada di Karawang Barat, sedangkan di bagian Karawang Timur terletak rumah menengah bawah, lahan pertanian dan lahan kosong yang belum difungsikan.

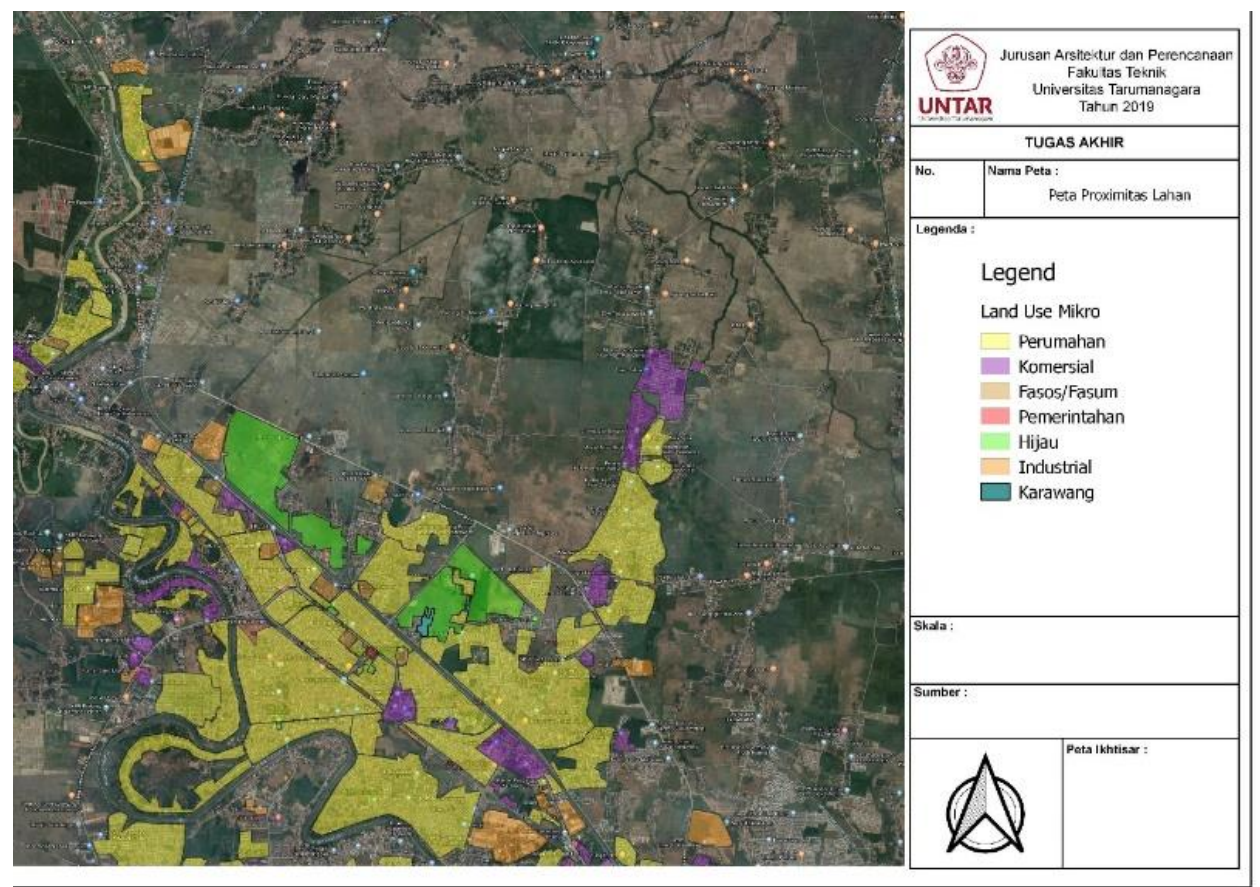

Gambar 1. Peta Land Use Proximitas

Sumber: Penulis, 2019

Tabel 1. Proximitas

\begin{tabular}{|c|c|c|c|}
\hline NO & Lokasi & Jarak Menuju Lokasi & Waktu Tempuh \\
\hline 1 & Bandara Halim & $59 \mathrm{Km}$ & 1 Jam 15 menit \\
\hline 2 & Kota Karawang & $2,2 \mathrm{Km}$ & 7 menit \\
\hline 3 & Jakarta & $72 \mathrm{Km}$ & 1 jam 40 menit \\
\hline 4 & Bandung & $98 \mathrm{Km}$ & 1 Jam 37 Menit \\
\hline 5 & $\begin{array}{l}\text { Kawasan } \\
\text { Industri }\end{array}$ & $14 \mathrm{Km}$ & 30 menit \\
\hline
\end{tabular}

Sumber: Penulis, 2019 
Kapasitas ruang untuk lahan pengembangan menunujukkan luas lahan yang dapat dibangun, KDB dan KLB. Kapasitas ruang juga dapat disebut jumlah dan besarnya ruang yang dipengaruhi oleh kapasitas dalam ruangan. Kapasitas raugn dalam pengembangan biasa mengacu pada peraturan pemerintahan dan berfungsi sebagai batasan dalam pengembangan lahan. Kapasitas ruang untuk lokasi lahan antara lain:
a. KDB Maks
: $50 \%$
b. KLB Maks
$: 1$
c. Tinggi Bangunan
$: 2$
d. KDH Min
: $40 \%$
b. Analisis Legalitas

Tabel 2. Crosscheck Legalitas

\begin{tabular}{cllll}
\hline NO & Leaglitas & Eksisting & Komparasi \\
\hline 1 & Harga lahan maksimal Rp 150.000/m2 & Harga Lahan Rp $100.000 / \mathrm{m} 2$ & Sesuai \\
\hline 2 & $\begin{array}{l}\text { Lahan sudah bersertifikat, karena } \\
\text { pembuatan sertifikat relatif mahal }\end{array}$ & biaya & Lahan sudah bersertifikat & Sesuai \\
\hline 3 & $\begin{array}{l}\text { Sesuai RUTRK (rencana umum tata ruang } \\
\text { kota) masuk zona kuning (perumahan) }\end{array}$ & $\begin{array}{l}\text { Zona kuning bergaris } \\
\text { (permukiman kepadatan tinggi) }\end{array}$ & Sesuai \\
\hline 4 & $\begin{array}{l}\text { Status lahan di sertifikat sudah pekarangan } \\
\text { (bukan sawah atau pertanian), supaya tidak } \\
\text { perlu melakukan alih fungsi lahan }\end{array}$ & Lahan sudah bersertifikat & Sesuai \\
\hline 5 & $\begin{array}{l}\text { Eksisting lahan bukan sawah, supaya tidak } \\
\text { perlu melakukan urugan atau penimbunan } \\
\text { yang relatif mahal }\end{array}$ & $\begin{array}{l}\text { Lahan eksisting masih berupa } \\
\text { lahan kosong bekas pertanian }\end{array}$ & $\begin{array}{l}\text { Belum } \\
\text { Sesuai }\end{array}$ \\
\hline 6 & $\begin{array}{l}\text { Eksisting lahan bukan bukit berkontur karena } \\
\text { melakukan pekerjaan cut and fill }\end{array}$ & Eksisting lahan berkontur landai & Sesuai \\
\hline 7 & $\begin{array}{l}\text { Dalam radius } 5 \text { km harus ada potensi market } \\
\text { sebesar 50x dari jumlah unit yang dipasarkan } \\
\text { (disarankan dekat dengan kawasan ind ustri) }\end{array}$ & $\begin{array}{l}\text { Dalam radius } \\
\text { distrik industrial }\end{array}$ & km terdapat & Sesuai \\
\hline
\end{tabular}

Sumber: Penulis, 2019

Sudah hampir semua legalitas yang dikenakan dari pemerintah ke lokasi lahan sudah terpenuhi hanya kurang pengolahan lahan yang bersawah hal ini mempengaruhi biaya pematangan tanah yang dikenakan biaya ekstra agar lahan layak untuk dibangun.

\section{Analisis Objek Studi}

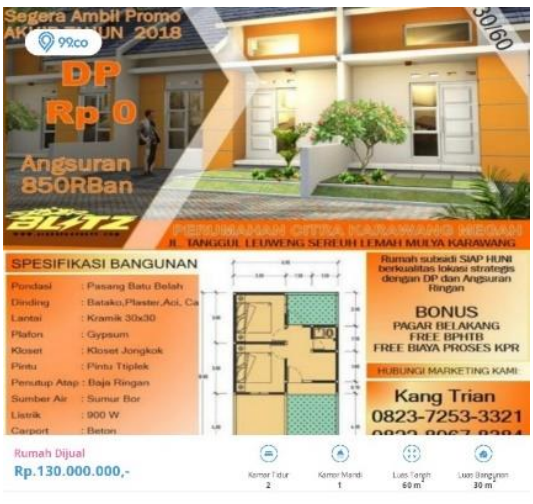

Gambar 2. Desain dan Lokasi RSS Citra Karawang Megah

Sumber: www.citrakarawangmegah.com 


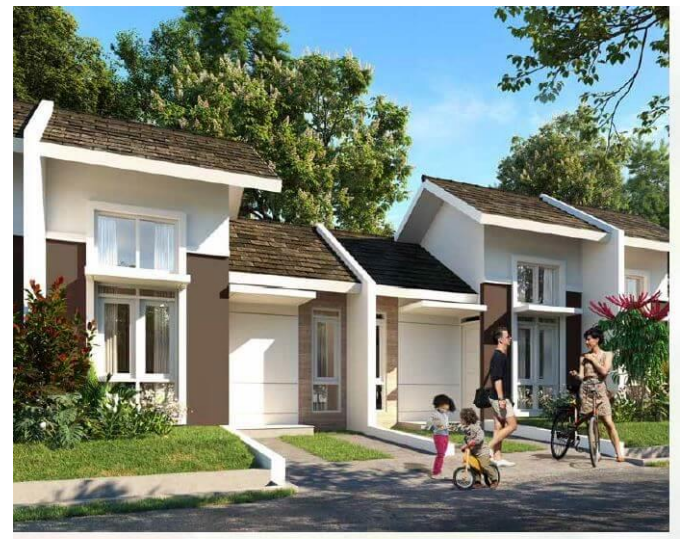

tipe

CALLA LB 22 LT $60(5 \times 12)$

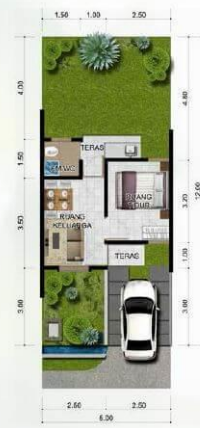

Gambar 3. Desain dan Lokasi RSS Citra Karawang Megah Sumber: www.citra-maja-raya.com

Kedua rumah merupakan rumah subsidi dengan perbedaan desain exterior yang akan digunakan dalam analisis Rencana Anggaran Biaya dan analisis preferensi, keduanya memiliki luas lahan dan kavling yang sama namun pengembang yang berbeda. Dengan memperbandingkan kedua rumah tersebut dapat terlihat bahwa citra Karawang memiliki desain yang lebih simple dan Citra Maja memiliki desain yang leibh mewah, sesuai dengan desainnya harga jual CKM lebih murah menandakan ada hubungan antara desain bangunan dengan harga jual d. Analisis Preferensi

Grafik 1. Pendapatan per bulan pekerja industri

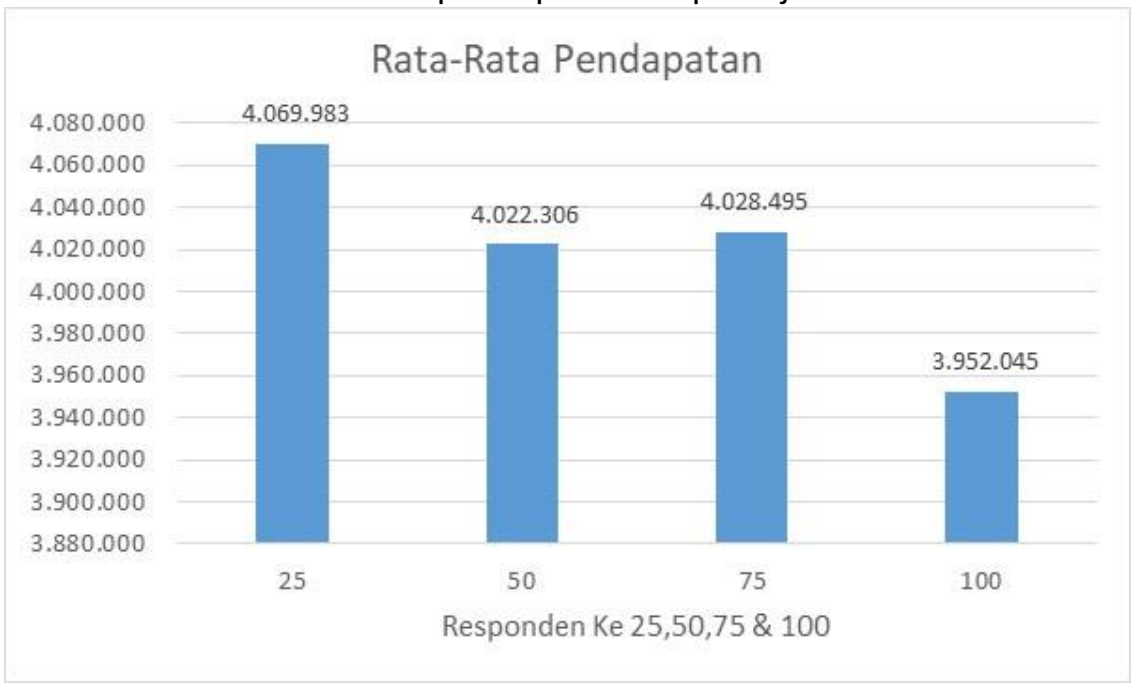

Sumber: Penulis, 2019

Grafik diatas menunjukkan bahwa rata rata pendapatan hingga respnden ke 75 memiliki pendapatan lebih dari 4 juta sedangkan sisanya 3,9 juta, namun menurut perhitungan pendapatan per bulan mayoritas diatas 4 jt artinya cicilan per bulan yang dapat dilakukan oleh calon pembeli yakni 30\% dari 4 jt artinya jika gaji pekerja sekitar 4,5 juta maka cicilan yang akan mereka bayarkan adalah 1,15 juta per bulan. Dengan rata rata pendapatan atau gaji yang didapat oleh karyawan industri di Karawang yakni Rp. 4.018.207. 
Grafik 2. Pengeluaran per bulan pekerja Industri

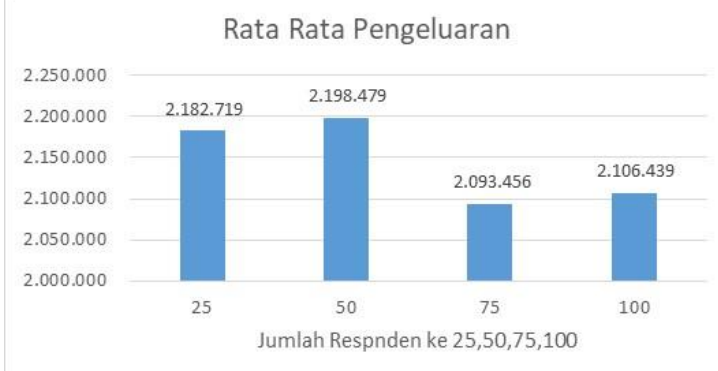

Sumber: Penulis, 2019

Rata rata pengeluaran dari 1,5 hingga 2,5 juta angka ini dibagi berdasarkan keperluan sehari hari dari pekerja yakni transportasi, pangan, pajak dan aktivitas lainnya, pengeluaran per bulan berdasarkan hasil kuesioner yakni sebesar Rp. 2.145.273

\section{Analisis Keuangan}

Analisis keuangan meliputi beberapa subjek yakni Rencana Anggaran Biaya, Harga Pokok Penjualan serta analisis sensitivitas keuangan yang variabelnya meliputi lama penjualan unit rumah dan harga konstruksi rumah yang digunakan.

Tabel 3. RAB per m2 Rumah Subsidi Tipe 30/60 dengan Kerjasama dan Harga Real

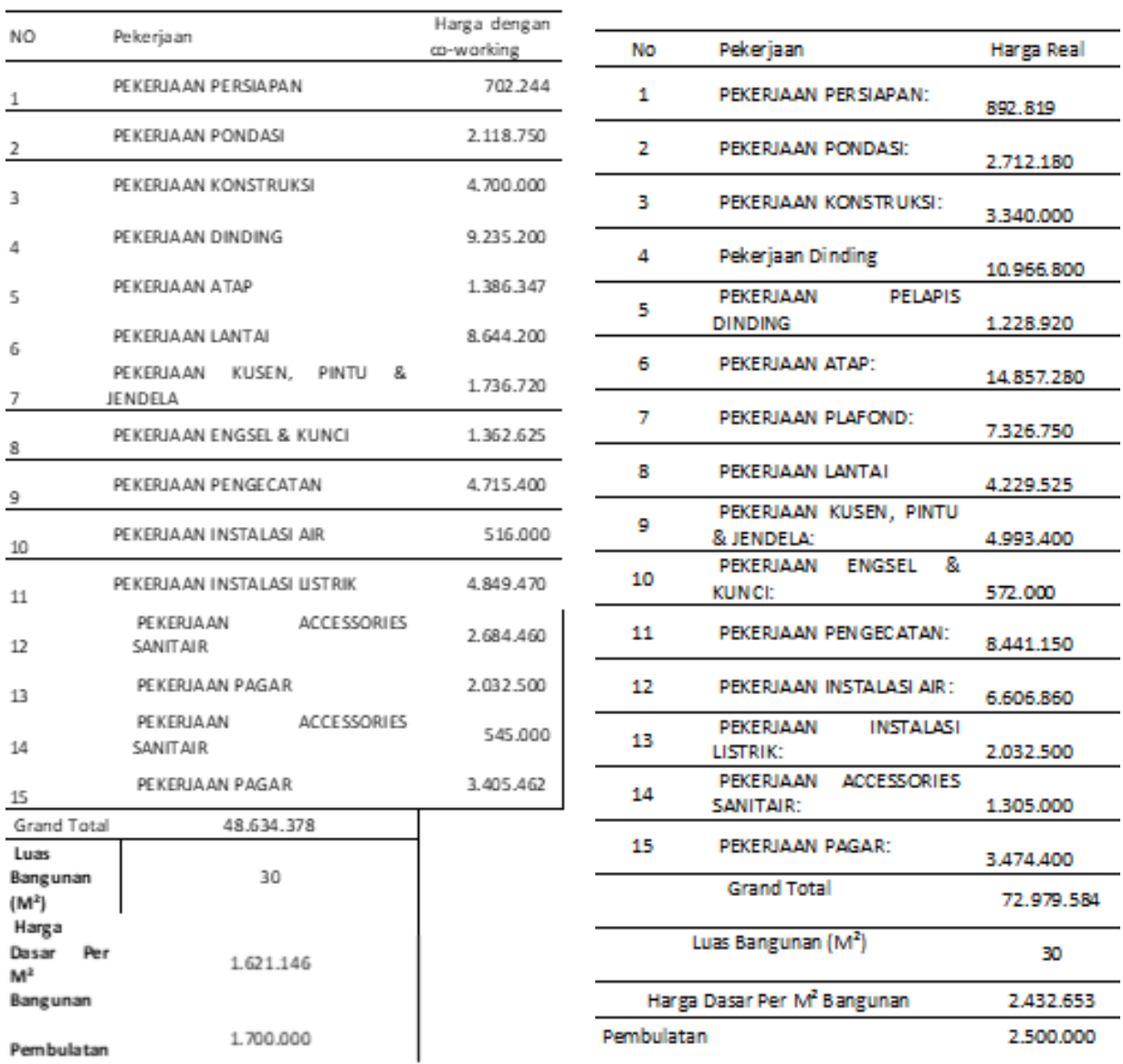

Sumber: Penulis, 2019 
Harga konstruksi rumah dengan menggunakan co working yakni adanya kerjasama antara pengembang dengan supplier langsung yang menyebabkan harga satuan dari beberapa item menjadi lebih murah daripada harga real pasar, contohnya dapat dilihat di harga lantai dan harga pekerjaan pintu di sisi harga pasar hampir 2 kali lipat harganya angka ini akan berpengruh kepada perhitungan akhir pada analisis keuangan dan kelayakan investasi.

Tabel 4. Tabel HPP \& Harga Jual

\begin{tabular}{ccccc}
\hline & Harga Satuan & Luas & vol & Total \\
\hline Tanah & 100.000 & 28.000 & 1 & 2.800 .000 .000 \\
\hline Infrastuktur & & & & 3.759 .483 .600 \\
\hline Pengolahan Tanah & 167.000 & 280 & 60 & 2.805 .600 .000 \\
\hline Bangunan & 1.700 .000 & 280 & 30 & 14.280 .000 .000 \\
\hline Total & & & & 23.645 .083 .600 \\
\hline Kavling & & 105.513 .691 & \\
\hline Harga Jual & & &
\end{tabular}

Sumber: Penulis, 2019

Harga Pokok Penjualan (HPP) merupakan total keseluruhan biaya yang dikeluarkan secara langsung oleh suatu perusahaan untuk mendapatkan barang atau jasa yang dijual. Perhitungan HPP dilakukan dengan tujuan untuk mengetahui besarnya biaya produksi yang akan dikeluarkan oleh perusahaan saat akan memproduksi barang atau jasa. Pada umumnya perhitungan Harga Pokok Penjualan (HPP) terdiri atas biaya beli tanah, biaya infrastruktur dan biaya konstruksi rumah. Dapat dilihat harga yang lebih mendekati harga jual asli yakni harga real namun perlu dilihat lagi apakah jika menggunakan harga tersebut pengembang mendapatkan keuntungan atau tidak. Tabel diatas menunjukkan harga jual dengan harga bangunan yang dipengruhi oleh factor kerja sama antara pengembang dengan supplier, hal ini menghasilkan HPP yang lebih rendah dari standar harga jual rumah subsidi yakni pada thun 2019 Rp 140 juta.

Tabel 5. Tabel HPP \& Harga Jual

\begin{tabular}{ccccc}
\hline & Harga Satuan & Luas & vol & Total \\
\hline Land Development & 100.000 & 28.000 & 1 & 2.800 .000 .000 \\
\hline $\begin{array}{c}\text { Infrastuktur } \\
\text { Pengolahan Tanah }\end{array}$ & 167.000 & 280 & 60 & 3.759 .483 .600 \\
\hline Bangunan & 2.500 .000 & 280 & 30 & 21.000 .000 .000 \\
\hline Kavling & & & 31.083 .833 .600 \\
\hline HPP & \multicolumn{3}{|c}{111.013 .691} \\
\hline Harga Jual & & 132.080 .656 \\
\hline
\end{tabular}

Sumber: Penulis, 2019

Tabel diatas perbedaannya terletak pada bahwa perhitungan konstruksi rumah dilakukan berdasarkan harga real yakni harga pasar dapat dilihat bahwa HPP yakni 132 juta mendekati harga jual standar rumah subsidi yakni 140 juta rupiah. Dalam perhitungan ini cashflow akan dihitungan dengan tujuan mencari NPV,IRR dan PI yang berkaitan dengan keuntungan yang akan didapatkan developer. Perhitungan ini juga memiliki beberapa variable yang sensitive yakni harga konstruksi perumahan, jumlah unit yang dapat terjual, besaran suku bunga bank yang mempengaruhi IRR dan biaya tanah. 


\section{Optimis}

Dalam perhitungan optimis factor yang digunakan adalah:

- Unit habis terjual

- Suku bunga tetap

- Harga rumah yang murah karena adanya kerjasama antar supplier dengan pengembang

- Biaya tanah dibawah harga maksimal

Tabel 6. Nilai Optimis

\begin{tabular}{cc}
\hline Net Present Value & Rp1.462.231.513,64 \\
\hline Internal Rate of Return & $34 \%$ \\
\hline Payback Period & 3 years \\
\hline Profitability Index & 1,0353 \\
\hline Average Rate of Return & $16,0 \%$ \\
\hline
\end{tabular}

Sumber: Penulis, 2019

Tabel diatas menujukkan bahwa proyek tersebut akan menghasilkan keuntungan dengan IRR 34\% yang lebih besar dari bunga bank yakni $12 \%$ dan pengembaliannya sebesar 3,5 \% lebih besar dari investasi awal

\section{Moderate}

Dalam perhitungan optimis factor yang digunakan adalah:

- Unit habis terjual

- Suku bunga tetap

- Harga rumah berdasarkan harga jual pasar terkini

- Biaya tanah dihitung secara total

Tabel 7. Nilai Moderate

\begin{tabular}{cc}
\hline Net Present Value & Rp1.323.771.205,24 \\
\hline Internal Rate of Return & $33 \%$ \\
\hline Payback Period & 3 Tahun \\
\hline Profitability Index & 1,0322 \\
\hline Average Rate of Return & $15,0 \%$ \\
\hline
\end{tabular}

Sumber: Penulis, 2019

Tabel diatas menujukkan bahwa proyek tersebut akan menghasilkan keuntungan dengan IRR 33\% yang lebih besar dari bunga bank yakni $12 \%$ dan pengembaliannya sebesar 3,2 \% lebih besar dari investasi awal.

\section{Pessimis}

Dalam perhitungan optimis factor yang digunakan adalah:

- Unit tidak habis terjual (masih tersisa)

- Suku bunga tetap

- Harga rumah berdasarkan harga jual pasar terkini

- Biaya tanah dihitung dengan asumsi baiaya tanah mengalami kenaikan per tahun 
Tabel 8. Nilai Pessimis

\begin{tabular}{cc}
\hline Net Present Value & Rp1.188.538.033,56 \\
\hline Internal Rate of Return & $26 \%$ \\
\hline Payback Period & 3 Tahun \\
\hline Profitability Index & 1,0282 \\
\hline Average Rate of Return & $16,9 \%$ \\
\hline
\end{tabular}

Sumber: Penulis, 2019

Tabel diatas menujukkan bahwa proyek tersebut akan menghasilkan keuntungan dengan IRR 33\% yang lebih besar dari bunga bank yakni $12 \%$ dan pengembaliannya sebesar $2,82 \%$ lebih besar dari investasi awal

\section{KESIMPULAN DAN SARAN Kesimpulan}

Dengan segala analisis dan perhitungan yang dilakukan dapat ditarik kesimpulan bahwa desain rumah yang diminati oleh pembeli yakni desain yang menyerupai rumah yang berada di Citra Maja Raya dengan desain yang modern walupun harganya lebih tinggi dibanding harga ruamh subsidi di Karawang. Dalam perhitungan cashflow dapat terlihat bahwa perhitungan yang memenuhi syarat serta menghasilkan keuntungan terbesar adalah cashflow yang moderat. Alasan mengapa moderat yakni dalam perhitungan optimis walaupun keuntungannya lebih besar namun harga tanahnya jauh lebih murah dalam arti kata tidak logis, di lain pihak dalam hitungan pessimis nilai inflow yang didapat tidak bisa sebandingn dengan niali inflow yang diperlukan (hasil NPV,IRR dan PI hasilnya negative). Hasil dari analisis penulis yakni keuntungan proyek sebesar 3,2\% dengan NPV Rp 1.323.771.205,24 dan IRR 33\%.

\section{Saran}

Saran yang dapat diberikan yakni :

a. Promosi unit sangat penting dalam penjulana rumah subsidi, baiknya pnejualan maksimal 3 tahun sudah habis

b. Spektek yang digunakan boleh sama dengan rumah subsidi eksisting asalkan eksteriornya terlihat bagus dan sesuai preferensi pembeli

c. Analisis sensitivitas keuangan sangat membantu dalam menyaring data harga dan variabel yang akan mempengaruhi dan menghasilkan keuntungan pada developer.

\section{REFERENSI}

Barat, D. P. (2017, Desember 29). dishub.jabarprov. Retrieved from dishub.jabarprov.org: http://dishub.jabarprov.go.id/angkutan/kabkota/291.html

Jaffe, J. A., \& Sirmans, C. F. (2001). Fundamentals of Real Estate Investment. United State America: South Western/Thomson Learning.

Kusumastuti, D. (2015). Kajian Terhadap Kebijakan Pemerintah Dalam Pemberian Subsidi Di Sektor Perumahan. 17.

Kasmir. (2010). Pengantar Manajemen Keuangan. Jakarta: Kencana Prenada Media Group Nazir, M. (2005). Metode Penelitian. Jakarta: Ghalia Indonesia.

Slideshare.net. (2012, Maret 29). Retrieved from Slideshare.net: https://www.slideshare.net/infosanitasi/uu01-2011-perumahan-permukiman 
